\title{
Conceptualisation of community-based
} basic nursing education in South Africa: a grounded theory analysis

\author{
NG Mtshali, PhD \\ School of Nursing, University of KwaZulu-Natal
}

\section{Keywords:}

Community - based education; grounded therapy

\section{Correspondence address:}

Dr Ntombifikile Gloria Mtshali

School of Nursing.

University of KwaZulu-Natal, Durban 4041

Tel. : 031-2602499

Fax : 031-2601543

Email :mtshalin.3@ukzn.ac.za

\section{Abstract: Curationis 28(2): 5-12}

Community-based education is about a decade old in basic nursing education in South Africa. An extensive review of literature revealed that although CBE was a familiar concept in South Africa, there was however. limited understanding of what this phenomenon means. The purpose of the study was to analyse the concept 'community-based education' with the aim of discovering shared understanding of this phenomenon in basic nursing education within the South African context.

Strauss and Corbin's (1990) grounded theory approach was used to guide the research process. The South African Nursing Council's (SANC) education committee, the National Department of Health. human resources division representatives as well as seven nursing education institutions with well-established CBE programmes participated in the study. The data was collected by means of observations, interviews and document analysis. Purposive sampling and later theoretical sampling was used for selecting interviewees. This resulted in a total of 45 interviewees. The data collection and initial data analysis took place concurtently. Descriptive analysis followed by conceptual analysis was performed using Strauss and Corbin's model.

The findings in this study revealed that community-based education is education that uses the community extensively, especially the under-developed and under-resourced settings, for learning purposes in order to enhance relevance of nursing education to the needs of the South African population. The core discriminatory characteristics of CBE were found to include; primacy of the community as a learning environment; the early exposure of students to community-based learning experiences: community-based learning experiences dominating the curriculum. exposure to community-based learning experiences throughout the curriculum, vertical sequencing of community-based leaming experiences in a curriculum, starting from primary settings to secondary and later tertiary health care settings to facilitate the development of competencies required when serving in all these settings, and lastly. learning through providing service to the underresourced communities. Community involvement and partnership, problem-centred learning. valid assessment of learning emanated as important characteristics of CBE but which were identified as gaps in the existing programmes. Recommendations focused on these gaps as well as to the problem of community-based learning experiences which were mainly concentrated in first and/or second year levels in most of the programmes.

\section{Introduction}

One of the important developments in South Africa was the transformation of the Health Care System to a primary health care (PHC) approach. This development served as a major stimulus for change in health professionals' education, including nursing. A paradigm shift from hospital based, curativefocused education to PHC-oriented and community-based education was marked in the early 1990s. Increasing the number of community-oriented graduates with knowledge of primary health care, who would be able to serve the medically under-served areas was and still is a national concern in South Africa Community-based education (CBE) emerged as one strategy that could produce graduates of this nature. Currently, the number of nursing education institutions changing to community-based education (CBE) is rapidly increasing, thus making $\mathrm{CBE}$ a familiar concept in South Africa.

\section{Literature review}

This study employed a grounded theory 
approach, which does not support extensive review of literature during the initial stages of research. Complete immersion in literature is discouraged at this early stage as preconceived ideas about the precise nature of the phenomena and how other researchers have interpreted this phenomenon can colour the direction of the research (Donovan, 1995, p710). The initial literature search helped in illuminating gaps in the understanding of the term $\mathrm{CBE}$, and assisted in shaping and refining the research questions. Initial literature review attempted to make a distinction between CBE and community-oriented education (COE), as these terms are commonly used interchangeably. Part of the literature review included understanding of the term community and highlighting nursing education institutions running CBE programme in South Africa.

\section{Conceptualisation of community- oriented education}

The terms COE and CBE are sometimes used interchangeably mainly because they share some characteristics. Hamad (2000:15) defines COE as education that prepares health professionals to respond to priority health needs of a community, with the emphasis on health promotion and disease prevention. The focus of COE is on population groups and individual persons in the community, taking into account in all aspects of its operation, the health needs of the community concerned. Learning however does not necessarily have to take place in the community settings. According to Bor (2003:401) such training could be situated in community, university or other settings and augmented by distance learning. The emphasis in COE is that the curriculum should be driven by health needs and problems of the community but teaching and learning does not necessarily have to take place in community settings.

Hamad (2000:15) pointed out that as any institution with a slight degree of focus on the population and the needs of the community may unjustifiable claim to be community-oriented there is a need to elaborate further and evoke some quantification of the basic components of COE. Hamad suggested the following questions when evaluating a $\mathrm{COE}$ programme:

- How far are the aims, objectives and basic principles on which the educational activities are based determined by the needs and priority health problems of the community within which the institution exists? The emphasis here is on educational activities, not on a curriculum document which is not implemented.

- To what extent does the programme adopt a comprehensive approach (health promotion, prevention and rehabilitation) as opposed to focusing mainly on curative activities?

- How much does the training make use of resources available in the community and technology appropriate to it and how far does it provide for training students in real life situations in which they are likely to work after graduation?

- How much of the total training (what percentage) is based in the community at large and in peripheral health units (primary health care centres and clinics) rather than being limited to highly equipped teaching hospitals. Is there an appropriate balance in training to cover the whole spectrum of health care; primary, secondary and tertiary? Does this training start early enough and continue throughout the programme?

- How far the programme as a whole integrates with the health care system, thus promoting an integrated development of health services and human resources for health. Is there a functional partnership with the health system, health related sectors and community concerned?

- What are the indicators that the graduates will have ability and conviction to serve their community and perform particular duties which fulfils the objectives of COE, duties such as to mobilise, organise and inspire community and participate in community development activities; diagnose and manage priority health problems in the country at the individual, family and community levels and contribute to the promotion of health systems; function effectively within a health team, and so forth.

As stated in Schmidt, Magzoub, Nooman and Vluggen (2000: 15) it is important to note that $\mathrm{COE}$ is not aimed at producing community specialists but graduate who would be able to respond primarily to the needs of the community concerned. These graduates whether functioning in research units or speciality units should be characterised by their communityoriented approach, by being able to initiate activities and contribute to addressing the problem at its source rather than waiting to receive it at the end of the line in the clinic or hospital where it has already assumed advanced proportions which are hard to contain.

\section{Community-based education}

$\mathrm{CBE}$ is viewed as community-oriented education defined by the setting in which learning takes place, the community setting. According to Bor (1993: 401) learning in CBE takes place in a variety of settings resembling those in which graduates are likely to practice after graduation, but the community setting is used extensively. According to Uys, Botma and Crichton (2003:101) if community-based learning experiences are $50 \%$ or more that programme is community-based whereas if less than $50 \%$ that programme is communityoriented. A characteristic unique to $\mathrm{CBE}$ is that learning inherently takes places outside the classroom or teaching hospital (Magzoub and Schmidt, 2000:54). This means learning is no longer confined within the four walls of the classroom or hospital settings, a major part of it takes place in the community settings.

In the context of CBE the term community is defined as the total population of the region in which students are placed for learning purposes (World Health Organisation, 1987:8). It refers to a group of individuals and families living together in a defined geographic area, usually comprising a village, town or city. This group would require primary, secondary and tertiary care services (World Health Organisation, 1987:8).

Matteson (2000:3) highlights another distinctive characteristic of CBE that, CBE brings together three components; the members of the university (students and university staff), the providers of health care in the community, and the members of the community. According to this author CBE embraces and values the knowledge and skills of all participants (faculty, students, providers and residents) because they all learn from each other. It enables the participants to work collaboratively to improve the health of individuals, groups, and the neighbourhood as a whole while educating faculty and students in the realities of patient or client lives. These three partners are crucial in enhancing relevance and responsiveness of education to the needs of the population. In conclusion, the features 
distinguishing CBE from COE is firstly, the setting where learning takes place, secondly, the total percentage of community-based learning experiences in a programme and thirdly, the degree of partnership between the academic institution, the community and the health care sector. The curriculum determinants as well as the focus of the curriculum and purpose of education are the same.

\section{Community-based nursing education in South Africa}

In South Africa, CBE programnmes are reported in a number of nursing education institutions. The University of Natal, School of Nursing introduced CBE in 1994 (Gwele, 1997:275; Uys, 1998:9), the Witwatersrand, School of Nursing changed to CBE in 1995 (McInerney, 1998:3), the University of the Free State, School of Nursing (Fitchard \& du Rand, 2000:3; Fitchard, Viljoen, Botma and du Rand, 2000:86) as well as the University of the Transkei, School of Nursing (Madalane, 1997:3; Nazareth and Mfenyane, 1999:722) adopted CBE in 1997. Frere College of nursing piloted $\mathrm{CBE}$ in 1997 and changed the curriculum in 1998. CBE is also reported in the University of the Western Cape, Transkei College of Nursing and its seven satellite campuses (Mtshali: 2003:92) and other institutions are in a process of change.

The analysis of the existing CBE programmes revealed that their focus vary from service-oriented programmes with less emphasis on learning, to those balancing learning and provision of service, and those placing more emphasis on learning than service provision. Some programmes have some degree of a research-oriented focus with the students used to collect data about outbreaks in communities, such as bilharzia. malaria, cholera, and so forth. One assumes that these variations in the focus of existing CBE programmes is attributed to the different understandings of what the concept CBE entails.

\section{Problem statement}

Several factors have been identified as the causes of the apparent lack of the consensus in the understanding of CBE. Firstly, community-based basic nursing education in South Africa arose in the early 1990s as a "reaction" to the realization of the inadequacy of traditional health education programmes in preparing graduates with relevant knowledge and skills to meet the health needs of the community. Secondly, the transformation of the health care system in South Africa, with PHC as an underlying policy required urgent reform in the preparation of health professionals. This sudden realization and reaction almost precluded any form of professional and/or intellectual discourse of what the phenomenon CBE means and/ or entails. The result has been the evolvement of a number of "unconnected" and unrelated CBE programmes in the country. It is appreciated that the diversity provides a rich and vibrant nursing education environment in the country, but a problem arises in the nature of such diversity, as they indicate obvious lack in the understanding of what CBE entails. According to Towle (1992:4), the lack of clarity on the concept of CBE leads to inconsistencies of approaches and mixed messages to people, and that is likely to affect expected outcomes of CBE. The inconsistency in existing CBE programmes in South Africa revealed a need for shared views on this phenomenon in order to facilitate a meaningful practice of $C B E$ in basic nursing programmes.

\section{Purpose of the study}

The purpose of the study was to analyse community-based education with the aim of discovering shared conceptualisation of this phenomenon in basic nursing education within the South African context.

\section{Objectives of the study}

The objectives of this study were to (a) analyse the phenomenon $\mathrm{CBE}$ and the meaning attached to it in various nursing education institutions, and (b) describe the conceptualisation of the phenomenon $\mathrm{CBE}$ in basic nursing education programmes in South Africa.

\section{Ethical considerations}

This study was conducted for academic purposes, therefore ethical clearance to conduct this study was obtained from the university's research ethics committee. Permission was sought from heads of schools that participated in this study as well as from the South African Nursing Council (SANC) and the National Department of Health (policy makers). Informed consent was obtained from participants. Participation was voluntary, gathered data was treated with confidentiality and code numbers were used to identify participants.

\section{Operational definitions}

\section{Community-based education:}

Community-based education is defined as means of achieving educational relevance to community needs and, consequently, as a way of implementing a community-oriented educational programme. It consists of learning activities that utilize the community extensively as a learning environment in which not only students, but also teachers, and members of the community are actively involved throughout the educational experience. Depending on how the population is distributed the learning environment may be an urban, suburban or rural community" (WHO, 1987:8).

\section{Basic nursing education:}

Basic education refers to comprehensive education of nursing students leading to registration as a nurse (general, community, and psychiatry) and midwifery.

\section{Research methodology}

A qualitative design and a grounded theory approach were used in this study. A grounded theory approach was appropriate in this study as it is a method known for its ability to make greatest contribution in areas where little research has been done and when new viewpoints or gestalts are needed to describe the familiar phenomenon that is not clearly understood (Chenitz \& Swanson, 1996:7). As according to Stern (1994:213) there are two main methodological schools in grounded theory; one by Glaser and another by Strauss and Corbin, Strauss and Corbin's approach was more appropriate in this study.

\section{Setting description}

In grounded theory the selection of settings is directed by theoretically relevant concepts. Therefore the researcher selected settings that will provide relevant and rich data. In this study, the criterion for inclusion of the setting was determined by the existence of a well-established community-based basic nursing education programme. The settings included four university nursing schools with well-established CBE programmes and two nursing colleges and their satellite campuses. 


\section{Sampling procedure}

Participants selected in grounded theory should be rich in information, as Creswell (1998) stated that participants are selected on the basis of their ability to contribute to the development of theory. More importantly, it requires an interactive process of data collection, coding, analysis and planning what to study next, which in this particular study was enhanced through purposive sampling and theoretical sampling. Purposive sampling, according to Merriam "is based on the assumption that the investigator wants to discover, understand, and gain insight and therefore must select a sample from which most can be learned" (1998: 61). Theoretical sampling, on the other hand, is a process of data collection for developing a theory whereby the analyst collects, codes and analyses data and decides what data to collect next and where to find them in order to develop a theory as it emerges (Glaser \& Strauss, 1967:62). The process of data collection in theoretical sampling was controlled by the emerging theory (Glaser, 1998:36). The researcher interviewed CBE programme directors and/or heads of schools, level coordinators and facilitators involved in community-based learning experiences. Policy makers; the South African Nursing Council Education committee members as well as the National Department of Health Human Resources representatives, participated in this study. Theoretical sampling was followed until the stage where saturation was achieved, with the total sample size of 45 participants. According to Glaser and Strauss an adequate sample is determined by the judgement of the researcher, but occurs when further sampling fails to reveal additional categories, properties, or relationships. The researcher must make a decision to discontinue collecting data and proceed to another research step (1967:63)

\section{Data collection process}

The collection of rich data was intensified by having two phases of data collection and through the use of multiple sources of data; observations, documents and interviews. The first phase was directed towards examining and analyzing the practice of CBE in selected nursing schools. During this phase the researcher spent a minimum of three days on each site mainly doing observations and analyzing documents.
The analysis of documents continued also between different sites visits. Observations included looking, listening and asking of questions. The researcher observed the phenomenon of CBE as it occurred in community learning settings and also observed how learning in the community was transferred to classrooms. Events were documented as they occurred in the form of field notes.

The second phase of data collection focused on interviews, which were informed by the data collected during observations. Interviewing participants was in line with the emphasis on asking questions as a primary tool of collecting data in a grounded theory. In the words of Glaser:

Observational data is not enough. The researcher should provide interviews along with observations so that the analyst can get a meaning of what is observed. Observations do not in and of themselves have the meaning or perspective in them of the participants (1992: 49).

Observations helped the researcher to gain an understanding of what was practiced as CBE and interviews on the other hand brought forth the participants' understanding of, and the meaning behind what was practiced as CBE in the community and classroom settings. The questions used for interviews were flexible and exploratory in nature as the researcher was directed by the participants' responses to probe further on issues of interest.

\section{Data analysis}

The QRS NVIVO programme was used to organize data and Strauss and Corbin's (1990:96) process of data analysis was followed. According to Strauss and Corbin, at the heart of grounded theory are three coding procedures; open coding, axial coding and selective coding. Open coding during data collection until the stage where theoretical saturation is reached, with no new categories emerging from the process. It involves diving data into concepts, categories of concepts, assigning properties, dimensions of properties along the continuum, and breaking properties into dimensions (Strauss and Corbin, 1990: 61 ). Out of the open coding process evolve additional questions that need to be asked and data, which needs to be examined until the stage where no new categories emerge from the process. Axial coding according to Strauss and Corbin, involves procedures for connecting categories found in open coding. Coding processes concern matching "conditions, context, action/interaction strategies and consequences (1990:96). Selective coding on the other hand is the process of selecting the core categories identified in the analysis and relating it on a systematic way to the other categories uncovered in the research.

\section{Results}

Four themes emerged as core discriminatory characteristics of CBE in basic nursing education in South Africa; the primacy of community as a learning environment, timing of first community exposure, duration and frequency of community exposure, and service provision. These themes were uncovered from all three data sources. Other themes, which emerged as important but from two data sources, were community participation and involvement, collaboration with the health care system and the community, problem-centred learning, multi-disciplinary team approach and valid performance assessment. These themes emerged as important theoretically but implementing them practically was a challenge, thus making the first four themes as important features, currently in what is practiced as $\mathrm{CBE}$ in basic nursing in South Africa.

\section{Primacy of community as a learning environment}

The results made it clear that the setting where learning takes place in CBE is crucial because the environment used in $\mathrm{CBE}$ is more than just a place of learning as was the case in traditional education. The communities selected should have special features to provides students with rich and diverse learning experiences. Most of the communities which were used for the placement of students had limited access to health services either due to accessibility of the services (distance) or affordability (due to poverty). The students had an opportunity to come into contact with the wider community, have first hand experience of realities in under-resourced communities and developed a better understanding of how the social, political and cultural factors contribute to health or ill health, as stated in the following extract.

Unlike in traditional nursing education, communities used in CBE are carefully 
selected. In our school for example, we are surrounded by affluent communities. For our CBE programme to materialise we are placing our student in a community that is more than $30 \mathrm{~km}$ away from our school. We were looking for a community with special characteristics..

Data sources also revealed that the nature of community settings selected enabled learners to learn about PHC be involved in PHC oriented activities in order to develop PHC related competencies.

\section{Timing of first community exposure}

This study revealed that the first community exposure in a CBE curriculum should be as early as possible in a programme. The students were introduced as early as in first year and second year to community-based learning experiences in order to lay a foundation early in PHC and communityfocused practice, not hospital focused practice. The first community exposure was either in the community per se or in community-based organizations, as stated by the following participants:

First exposure should be as early as possible in the programme. For example in our school their first exposure to community-based learning activities is in first year, as part of the PHC module.

In our institution the first year students are placed in community-based organisations to assess self-care needs of healthy individuals of all age groups, crèches, old age homes, etc and in second year are placed in community settings. In fourth year, the mental health care module is also community-based.

It is however important to note that only three of the seven nursing education institutions that participated in the study had community-based learning experiences in third and fourth year.

\section{Duration, frequency and sequencing of learning experiences}

The duration of community-based learning experiences in relation to hospital-based learning emerged as crucial in a programme referred to as community-based. The participants emphasized that community-based learning experiences should be spread throughout the curriculum, from the first year in the programme up to the fourth year and community-based learning activities focusing on health promotion and illness prevention were traced at all levels in most of the CBE programmes. Some of the participants were precise about the percentage of the time to be dedicated to community based learning experiences in a CBE programme. According to the data sources at least $50 \%$ of the programme should be dedicated to community based learning activities, as in the following extract:

In a community-based programme learning should take place in a balanced variety of setting with $50 \%$ or more of the time spent in activities taking place in community settings and the rest of the time spent in other settings. We believe that the longer the exposure to community-based activities the better are the chances of producing graduates with interest in serving the needs of the community.

Learning experiences in a CBE curriculum were vertically sequenced in such that they promoted continuity in learning, learning about healthy individuals first in their natural settings (family and community settings) and later hospitalised ones. Placing the students in community setting prior to placing them in hospital settings promoted provision of contextualised and individualized care in hospitals settings. The students learn to appreciate and consider the patients' context when rendering nursing care and when drawing discharge plans. One interviewee stated The arrangement of community-based learning experiences facilitate the understanding of the clients in their normal environment first so that by the time the students meet them in hospital, they have a better understanding of the clients' context and what is relevant with regard to their health education

More importantly, the findings revealed that the sequencing of learning experiences in a CBE curriculum facilitated the understanding of different levels of health care (primary, secondary and tertiary), the development of competencies required at each level of care and the understanding of how the health care system functions, as well as the referral system and lines of communication in the new health care system.

\section{Education for service}

CBE was also conceptualised as education incorporating learning as well as service rendering, rendering service especially to under-resourced communities with limited access to health care. Services rendered included home visits, health screening, blood pressure monitoring, glucose levels monitoring, wound care/dressings, health promotion and illness prevention programmes, and many other, while learning work related competencies, as stated in the following quote:

The students engage in learning activities which are educational as well as a form of service especially to underresourced communities. For example, our students conduct home visits. During those visits they do health education, teach families things like preparing oral rehydration solutions, check blood pressures, do glucose monitoring for those with diabetes, do wound dressings, and many other things.

In other institutions the term CBE was used interchangeably with service learning because of the strong service component embedded in $\mathrm{CBE}$, as stated in the following quote.

We do not really differentiate between service learning and $\mathrm{CBE}$ in our department because CBE incorporates both provision of service and learning, and both are important. Another reason for assuming they are similar is that the Service Learning Policy of our university serves as a reference or provides the context within which our CBE curriculum is based.

Data sources also revealed that students learn important nursing values while providing service to the community. The conceptual frameworks of all the institutions and some of the assignments given to the students highlighted a number of nursing values observed during the process of providing service to the community. It also emerged from interviews that the student unaware learned to apply these values during service rendering. More importantly, learning in under-resourced communities enhanced in some of the students the development of interest and compassion in serving in settings of this nature.

\section{Discussion of results}

The conclusion drawn from this study was that CBE in basic nursing programmes is characterised by four distinctive features. The community in 
the context of $\mathrm{CBE}$ was viewed as more than just a learning space. This setting exposes students to live dynamic contexts, and realities of life where students were able to link theory to the real world thus making learning more meaningful. Through this setting the students were conscientised to the social issues and injustices influencing health, as well as other determinants of health. The learning experiences in communities equipped students with competencies required in addressing issues and health problems prevalent in communities. The community setting provided the students with a comprehensive view of a patient/ client, not just a diseased individual. More importantly, preparing students in community settings was hoped to influence their career choices; with graduates ultimately choosing to serve in settings resembling those in which they were trained.

Early exposure of students to communitybased learning experiences, especially in PHC settings and underserved communities and then later to learning experiences in tertiary health care settings was crucial in curriculum viewed as community-based. Studies have supported positive impact of early exposure. For example, McLean (2004:43) asserted that early exposure is of importance in that students recognize the need to prepare for community and PHC settings from early in the programme. The students develop insight early of what a PHC oriented health system requires and skills required to serve in PHC settings are developed as early as possible. It emerged in this study that although early exposure to community-based learning experiences might be viewed as "early indoctrination" of students with $\mathrm{PHC}$, it facilitates the building of a good PHC foundation, developing a culture of promoting health and preventing illness irrespective of the setting where the students are placed, even in hospital where curative care is the focus. More importantly, through exposure to hands on real life experiences, the students learn to assist in addressing the health needs of the population, as early as possible in their career life.

Snadden and Mowat (1995:298) viewed sequencing of learning experiences from the healthy individuals to the sick as a key to meaningful teaching/learning in community-based learning. Vertical organisation of learning experiences is essential in a curriculum that is aimed at producing graduates competent in rendering comprehensive health care, and who would be able to function at all levels of health care. Such sequencing ensures that the students have an opportunity to develop competencies required at each level of health care. They also learn to provide care that is individualised, holistic and which takes into consideration the patients background.

CBE was also conceptualised in terms of the service provided and that service had a clear educational focus. In Kulewicz (2001:37) it is stated that learning of this nature developed from an educational philosophy that encourages active learning to fulfil social responsibilities. Over and above developing a sense of social responsibility, engaging in community-based learning experiences promotes learning that is more meaningful in that the students developed a better understanding of what is expected in their future careers. Although Dewey (1916:362) was referring to general education, he believed in preparing learners through occupations, as that made learning more real, more practical and relevant to future occupations. It is during the process of service delivery that the students develop work-related competencies, engaging in learning experiences closely resembling those of professionals in practice.

Learning through providing service as stated in Rodgers $(2001: 244)$, goes beyond learning cognitive and behavioural skills; it also facilitates the development of the affective aspect in students. Learning by providing service especially in underdeveloped communities facilitates the development of a compassion and sense of commitment to service. Kulewicz (2001:37), sharing a similar view, stated that learning through providing service encourages learning to fulfil social responsibilities. The students learn to contribute to the good of the community and develop a special interest in serving under-resourced communities. Moreover, exposing students to realities in community settings and working in partnership with communities facilitates the development of a number of important nursing values, such as, respect, autonomy, working with other people in partnership, altruism and social justice. Unaware, the students learn to apply these nursing values while interacting with the community. According to Kulewitz (2001:37), some of the core values learned include human dignity, respect, altruism, autonomy, integrity and social justice, as was also documented in reviewed documents.

Learning in under-resourced communities facilitates the development of interest in issues related to social injustices. According to Asbury (2002:2), as one becomes involved in the community, confronting community issues, they often want to know more about social issues prevalent in the community. They develop interest in social issues such as poverty, homelessness, domestic violence, the AIDS epidemic and many other contemporary social issues. As they learn through exploring these issues they develop a better understanding of them and how they impact on the lives of individuals in the community. In Asbury's view, because of the interest developed in social issues, when students provide service, they provide it with compassion, a service that has a meaning to both the provider and the receiver of the service

The service provided should however have a clear educational focus, as learning is the main purpose of providing service. Quinn, Gamble and Denham (2001:22) emphasized that academic institutions have an ethical obligation to see to the interests of the students, therefore service provision should be secondary to learning.

\section{Recommendations}

Community-based learning experiences were more marked in first and second year and traces if any were noted throughout the programmes. It is understandable that the basic nursing education programme is aimed at developing comprehensive graduates and the programme should prepare graduates in all these areas. Some of the programmes use the last year or two as specialisation years in midwifery and mental health with the focus on hospital care. In a CBE programme some of the aspects in these modules can be community-based. For example, the midwifery module can have students placed in communities for post-natal care, visiting families with newborn babies or following the mother and the child from the hospital back home to 
assist the mother during the first days post-natally.

Community involvement and partnership, collaboration between the health service sector and academic institutions, problem-centred learning that will inform the curriculum and valid assessment of learning emerged as important characteristics theoretically but as areas where problems were experienced practically. Research studies focusing on how these aspects could be enhanced in CBE curricula are recommended because these are some of the crucial aspects in the implementation of effective CBE programmes. The voices of the community and of the health service sector should be as loud as the voice of academic institutions in CBE programmes especially because these are the consumers of the product produced from these programmes. Evaluation should also be in line with the nature of the curriculum to ensure that the graduates produced meet the set curriculum outcomes.

\section{Conclusion}

According to the findings in this study, first, CBE in basic nursing programmes is viewed as education that uses the community extensively for learning purposes, with hospitals forming part of clinical learning settings used, not as the main setting for learning. Second, CBE is education that is able to produce graduates who are equipped to provide contextualised and individualised care, care that takes into consideration the client's physical, psycho-social, political, economic, cultural and many other factors impacting their health. Third, CBE is conceptualised as education that enhances relevance of nursing education to the needs of the South African population. This is achieved through a curriculum that is driven by the prevalent health problems in the clinical including community learning settings, the use of a variety of clinical settings that facilitate the development of expected graduate competencies as determined by the graduates' profiles in the work environment. Fourth, CBE emerged as an instrument used to prepare PHC oriented graduates, who are able to serve in primary health care settings and underresourced settings. In this regard $\mathrm{CBE}$ is viewed as one promising strategy to address the problem of skewed distribution of nurses where rural and under-resourced settings are confronted with a problem of retaining nurses. It is believed that early and prolonged exposure of students to these settings facilitated the development of interest in serving in settings of this nature. Fifth, $\mathrm{CBE}$ is conceptualised as education that facilitates the development of the sense of social responsibility in graduates and education that raises the consciousness of graduates to the social injustices impacting on the health of individuals, families and communities, especially the under-developed communities. Lastly, CBE facilitates the development of some nursing values, which are crucial in nursing practice. This is achieved through learning while providing service. More importantly, learning while providing service to clients helps in socialising students to their future professional roles and to the nature of settings where they are likely to practice after graduating. CBE is more than just learning in community settings it is education that facilitates academic as well as personal and professional development of students.

\section{Acknowledgements}

- The Health Systems Trust and the National Research Foundation. funders of this research.

- Professor NS Gwele, University of KwaZulu-Natal, School of Nursing: Research Supervisor

\section{References}

ASBURY, J 2002: Service learning and social justice. Retrieved November, 26, 2002, from http://www.rochester.edu/ chapel/communityservice.html.

BOADEN, N \& BLIGHT, J 1999: Community-based medical edcation: Towards a shared agenda for learning. London: Arnold

BOR, D 2003: Position paper on Community-based education for health professionals. Education for Health. 16, (3): $400-404$

CHENITZ, WC \& SWANSON, JM 1996: From practice to grounded theory: Qualitative research in nursing. Menlo Park: Addisons Wesley

CRESWELL, JW 1998: Qualitative inquiry and research design. Thousand Oaks, CA: Sage.

DEWEY, J 1916: Democracy and education. New York: McMillan

DONOVAN, J 1995: The process of analysis during grounded theory of men during their partners' pregnancies. Journal of Advanced Nursing. 21: 708715 .

HAMAD, B 2000: Community-oriented education: what it is? In H. Schmidt. M. Magzoub, G. Feletti, Z. Nooman, \& P. Vluggen. Handbook of community-based education: Theory and practices (pp.1126) Maastricht: Network Publications.

FITCHARDT, A \& DU RAND, P 2000: Facilitators' perceptions of problembased learning and community-based education. Health SA Gesondhuid. 5 (2): 3-10.

FITCHARDT, AE; VILJOEN, MJ; BOTMA, Y \& DU RAND, PP 2000: Adapting to and implementing problem and community-based approach to nursing education. Curationis. 3: 86-91.

GLASER, BG 1978: Theoretical sensitivity. Mill Valley, CA: Sociological Press.

GLASER, BG 1992: Emergence vs. forcing:basics of grounded theory analysis. Mill Valley, CA: Sociological Press.

GLASER, BG \& STRAUSS, AL 1967: The discovery of grounded theory: strategies for qualitative research. New York: Aldine De Gruyter.

GWELE, NS 1997: The development of staffs concerns during the implementation of problem-based learning in a nursing programme. Medical Teacher. 19(4): 275- 284

HOSPITAL AND NURSING YEAR BOOK OF SOUTHERN AFRICA 2000.

KULEWITCZ, SJ 2001: Service learning: Head start and a baccalaureate nursing curriculum working together. Pediatric Nursing. 27 (1): 37-41.

McLEAN, M 2004: Sometimes we do get it right. Early clinical contact is a rewarding experience. Education for Health. 17 (1): 42-52

MADALANE, LD 1997: Analysis of students' views concerning clinical supervision and learning opportunities 
in community settings. Unpublished master's thesis, University of Natal, Durban. South Africa.

MAGZOUB, M \& SCHMIDT, H 20M): Some principles involved in communitybased education. (In: H. Schmidt, M. Magzoub, G. Feletti, Z. Nooman, \& P. Vluggen (Eds). Handbook of communitybased education: Theory and practices (27-38). Maastrich: Network Publications).

MAGZOUB, M \& SCHNIDT, H 200): A taxonomy of community-based educational programmes. (In: H. Schmidt, M. Magzoub, G. Feletti, Z. Nooman, \& P. Vluggen (Eds). Handbook of communitybased education: Theory and practices (103-120). Maastrich: Network Publications).

MATTESSON, PS 2000: Communitybased Nursing Education: The experience of eight schools of nursing. New York: Springer Publishing Company.

MCINERNERY, PA 1998: Recurriculating to problem-based learning curriculum: The Wits experience. Curationis. (5): 53-56.

MTSHALI, NG 2003: A grounded theory analysis of the meaning of communitybased education in basic nursing education in South Africa. Unpublished Thesis. University of Natal, Durban: South Africa.

NAZARETH, I \& MFENYANE, K 1999: Medical education in the community- the UNITRA experience. Medical Education. (33): $722-724$

RODGERS, MW 2001: Service leaming: Resource allocation. Nurse Educator. 26 (5): 244-247.

\section{QUINN,SC; GAMBLE, D \& DENHAM,}

A 2001: Ethics and community-based education: Balancing respect for the community with professional preparation. Family Community Health. 23(4): 9-23.

SCHMIDT, HG; MAGZOUB, M; FELLETTI, G; NOOMAN, ZH \& VLUGGEN, S 2000: Handbook on community-based education. Maastrich: Network Publications.

SNADDEN, D \& MOWAT, D 1995 : Community-based curriculum development: What does it really mean? Medical Teacher. 17(3): 297- 306.

STERN, PN 1994: Eroding grounded theory. (In: J. Morse (ed.) Critical issues in qualitative research methods (pp. 212223). Thousand Oaks, CA: Sage).

STRAUSS, A \& CORBIN, J 1990: Basic qualitative research: Grounded theory procedures and techniques. Newbury Park CA: Sage Publications.

TOWLE, A 1992: Community-based teaching: Change in medical education. London: King Fund Centre.

UYS, LR 1998: University of Natal, School of Nursing. Network of Community-oriented Educational Institutions for Health Sciences Newsletter, 28: 19.

UYS, L; BOTMA, Y \& CRICHTON, A 2003: Approaches to learning: (In: Vasuthevan, S \& Viljoen, M (Eds) Educating for the better health: A handbook for health care professionals. Pages 99- 108. Lonsdowne: Juta).

\section{WORLD HEALTH ORGANISATION}

1987: Community-based education of health personnel. Report of the a WHO Study Group. Technical Report Series No. 746. Geneva. Switzerland: World Health Organization. 